\title{
Práticas informacionais de adolescentes na internet
}

\author{
Andrea Heloisa Goulart \\ Universidade de Brasília, Faculdade de Ciência da Informação, Brasília, DF, Brasil \\ andreagoulart@gmail.com \\ Ivette Kafure \\ Universidade de Brasília, Faculdade de Ciência da Informação, Brasília, DF, Brasil \\ ivettek@unb.br
}

DOI: https://doi.org/10.26512/rici.v12.n3.2019.20761

Recebido/Recibido/Received: 2018-12-18

Aceitado/Aceptado/Accepted: 2019-06-12

Resumo: A internet alterou a forma como os indivíduos lidam com a informação. Inúmeros dados comprovam que os adolescentes usam intensivamente a rede. $\mathrm{O}$ artigo apresenta pesquisa que objetivou investigar as práticas informacionais dos adolescentes na internet. Desenvolvido à luz do paradigma social de Capurro e da perspectiva das práticas informacionais, investigou-se como os adolescentes buscam, usam e compartilham informações na internet; quais os elementos externos que impactam nas suas escolhas; bem como a percepção da sociedade em relação à adolescência. O estudo parte de uma concepção pragmática, tem propósito descritivo, natureza básica e horizonte temporal transversal. A estratégia eleita foi a dos métodos mistos. Para atingir os fins propostos, foram entrevistados adolescentes e adultos. Os procedimentos metodológicos basearam-se no levantamento, no Discurso do Sujeito Coletivo e no estudo comparativo. Apurou-se que os jovens despendem tempo considerável na internet e são muito influenciados pelo meio em que vivem, sobretudo pelos amigos. Os adultos apresentaram uma percepção predominantemente negativa em relação a alguns comportamentos dos adolescentes, entendimento não confirmado na comparação com as práticas juvenis. Conclui-se que a web proporciona aos jovens inúmeras possibilidades de interação e acesso à informação, ao mesmo tempo em que os expõem a diversos riscos.

Palavras-chave. Adolescente. Estudo de usuários. Internet. interação com a informação.

\section{Information practices of adolescents on the internet}

Abstract: The internet has changed the way individuals deal with information. Numerous data show that adolescents use the network intensively. The article presents a study that aimed to investigate the information practices of adolescents on the Internet. Developed in the Capurro's social paradigm view and from the perspective of information practices, we investigated how adolescents seek, use and share information on the Internet; what external factors impact their choices; as well as society's perception regarding adolescence. The study starts from a pragmatic conception, has a descriptive purpose, basic nature and transversal temporal horizon. The strategy chosen involved mixed methods. To reach the proposed goals, adolescents and adults were interviewed. The methodological procedures were based on the survey, on the Discourse of the Collective Subject and on comparative study. It has been found that young people spend considerable time on the internet and are greatly influenced by the environment in which they live, especially by their friends. Adults presented a predominantly negative perception regarding some adolescents' behaviors, an understanding not confirmed in the comparison with the youth practices. It is concluded that the web offers young people numerous possibilities of interaction and access to information, while exposing them to various risks.

Keywords. Adolescent. User studies. Internet. interaction with the information. 


\section{Prácticas informativas de adolescentes en Internet}

Resumen: La Internet ha cambiado la forma en que los individuos se ocupan de la información. Numerosos datos demuestran que los adolescentes usan intensivamente la red. El artículo presenta una investigación que objetivó investigar las prácticas informacionales de los adolescentes en Internet. Desarrollado a la luz del paradigma social de Capurro y de la perspectiva de las prácticas informacionales, se investigó cómo los adolescentes buscan, usan y comparten información en Internet; que los elementos externos que impactan en sus elecciones; así como la percepción de la sociedad en relación con la adolescencia. El estudio parte de una concepción pragmática, tiene propósito descriptivo, naturaleza básica y horizonte temporal transversal. La estrategia elegida fue la de los métodos mixtos. Para alcanzar los fines propuestos, fueron entrevistados adolescentes y adultos. Los procedimientos metodológicos se basaron en el levantamiento, en el Discurso del Sujeto Colectivo y en el estudio comparativo. Se ha comprobado que los jóvenes gastan tiempo considerable en Internet y son muy influenciados por el medio en que viven, sobre todo por los amigos. Los adultos presentaron una percepción predominantemente negativa con relación a algunos comportamientos de los adolescentes, entendimiento no confirmado en la comparación con las prácticas juveniles. Se concluye que la web proporciona a los jóvenes innumerables posibilidades de interacción y acceso a la información, al mismo tiempo que los exponen a diversos riesgos.

Palabras clave: Adolescente. Estudio de usuarios. Internet. interacción con la información.

\section{Introdução}

A internet, o desenvolvimento de softwares, bem como a implantação de redes de fibra ótica em escala planetária levaram a humanidade a uma nova era, em que indivíduos são capazes de se conectarem uns com os outros instantaneamente e atuarem de forma global (FRIEDMAN, 2005). As tecnologias de informação e comunicação (TIC) promoveram a simultaneidade temporal, fazendo com que o distanciamento físico não mais corresponda ao distanciamento temporal (THOMPSON, 2008). Para Palfrey e Gasser (2011), o uso intensivo e disseminado da internet ocasionou relevante alteração no comportamento dos indivíduos e das organizações no que diz respeito à informação.

No caso dos adolescentes, diversas pesquisas apontam o alto índice de uso da internet por este público. Conduzido pelo Comitê Gestor da Internet no Brasil (2015), o estudo TIC Kids Online Brasil 2015, com crianças e adolescentes entre 9 e 17 anos, revelou que 84\% do público pesquisado usa a web diariamente ou quase todos os dias, $87 \%$ mantêm perfil em redes sociais e 80\% nelas compartilham suas fotos. De acordo com o Fundo das Nações Unidas para a Infância (UNICEF, 2013), a internet faz parte do cotidiano da maioria dos adolescentes e, além de constituir um espaço de interação e aprendizagem, também é ambiente de práticas agressivas e discriminatórias, abarcando riscos consideráveis como a possibilidade de violação de direitos e o uso indevido de informações.

Spizzirri et al. (2012) alertam para fato de que a maioria dos jovens não se submete a nenhum tipo de controle familiar em relação ao uso da rede. Assim, se por um lado, a internet assegura inúmeras possibilidades de interação, acesso à informação e exploração da 
criatividade, por outro, vulnerabiliza esta parcela da sociedade, sujeita às diversas ameaças contidas na rede.

Com isso, desenvolveu-se pesquisa a fim de analisar as práticas informacionais dos adolescentes na internet, com base no paradigma social descrito por Capurro (2003) e na perspectiva das práticas informacionais, sustentada por autores como Savolainen (2007) e McKenzie (2003). Para tanto, adotou-se abordagem interdisciplinar, em que o meio "internet" é visto à luz dos Estudos de Recepção, da Comunicação Social. De acordo com esta vertente, a comunicação entre emissor e receptor se dá pelo diálogo respaldado em referências culturais. Assim, o receptor apropria-se das produções midiáticas, resignificando-as a partir de suas próprias referências (BACCEGA, 2002; 1998). Sob este prisma, o adolescente é tido como coprodutor dos bens culturais e não apenas como espectador. Além disso, na exploração dos dados, foram utilizados conceitos da Análise do Comportamento e da Psicologia Social.

\section{0 paradigma social e a perspectiva das práticas informacionais}

Capurro (2003) apresenta três paradigmas epistemológicos que, em sua visão, predominam na Ciência da Informação (Cl): o físico, o cognitivo e o social. De acordo com o autor, a $\mathrm{Cl}$ inicia-se em meados do século $\mathrm{XX}$, apoiando-se num modelo fisicista, vinculado à Teoria Matemática da Comunicação de Shannon e Weaver e à cibernética de Wiener. Tal abordagem pressupõe a transmissão física de um sinal ou mensagem, sem que se leve em conta os aspectos semânticos e pragmáticos da informação, nem o papel ativo do usuário no processo informativo (CAPURRO, 2003). Desse modo, o paradigma físico volta-se aos sistemas informatizados, concentrando seu foco na mensuração da informação, sem qualquer preocupação com a semântica (ALMEIDA et al., 2007).

Em contraposição à perspectiva física, surge o paradigma cognitivo, influenciado, em grande medida, pela ontologia de Karl Popper. Este modelo enfoca o sujeito cognoscente, ao buscar compreender como os processos informativos transformam o usuário. Assim, a percepção de uma lacuna de conhecimento, por parte do indivíduo, em que os dados ao seu alcance não Ihe bastam para a resolução de determinado problema, acaba por levá-lo à busca de informação (CAPURRO, 2003). Por conseguinte, o foco das pesquisas desloca-se dos sistemas para o usuário e o seu conhecimento individual (ALMEIDA et al., 2007).

Na visão de Capurro (2003), contudo, o paradigma cognitivo apresenta lacunas, uma vez que compreende a informação como algo distinto do indivíduo, não enxergando o usuário como ser social. Com isso, o autor apresenta o paradigma social, que situa o sujeito socialmente e atrela os seus conhecimentos e os seus interesses às redes sociais das quais participa. Sob este 
prisma, a informação equivale a um fenômeno social, passível de receber influências tanto dos indivíduos quanto da coletividade (TABOSA; TAVARES; NUNES, 2016).

Na mesma linha, Hjørland (2002) entende que as necessidades de informação, suas estruturas, seus significados e os critérios de relevância são estabelecidos no âmbito das comunidades discursivas, de modo que o foco merece ser deslocado do indivíduo para o mundo social, cultural e científico. Araújo (2012) esclarece que, por esta ótica, a informação é construída socialmente e o sujeito é visto dentro do contexto em que está inserido.

Sob o prisma social surge, nos estudos de usuários, a perspectiva das práticas informacionais como alternativa às investigações de comportamento informacional, estas mais direcionadas ao comportamento individual e vinculadas ao paradigma cognitivo (ROCHA; DUARTE; PAULA, 2017). Ressalta-se, contudo, que tanto os estudos de "comportamento informacional" quanto os de "práticas informacionais" objetivam esclarecer como os sujeitos lidam com a informação, ainda que sejam distintos os seus pontos de vista (SAVOLAINEN, 2007). Segundo Berti e Araújo (2017), os primeiros intentam explicar como os usuários buscam informação a partir da identificação de uma lacuna de conhecimento, enquanto os últimos compreendem que a necessidade de informação se relaciona com o contexto sociocultural.

É nesse sentido que estudar as práticas informacionais constitui-se num movimento constante de capturar as disposições sociais, coletivas (os significados socialmente partilhados do que é informação, do que é sentir necessidade de informação, de quais são as fontes ou recursos adequados) e também as elaborações e perspectivas individuais de como se relacionar com a informação (a aceitação ou não das regras sociais, a negociação das necessidades de informação, o reconhecimento de uma ou outra fonte de informação como legítima, correta, atual), num permanente tensionamento entre as duas dimensões, percebendo como uma constitui a outra e viceversa (ARAÚJO, 2017, p. 220-221).

Assim, a noção de práticas informacionais permite que se compreenda como os indivíduos atribuem significados às suas ações relacionadas à informação (TABOSA; TAVARES; NUNES, 2016). McKenzie (2003) considera esta abordagem apropriada às investigações que envolvem relações cotidianas com a informação, uma vez que os usuários são tidos como membros de comunidades, as quais impactam suas atividades individuais. De acordo com Savolainen (2007), os estudos sob tal perspectiva centram-se nos elementos contextuais de busca, uso e compartilhamento de informação.

Nesse sentido, a pesquisa objetivou analisar as práticas informacionais dos adolescentes na internet. Em seu desenvolvimento, além de se averiguar como os jovens buscam, usam e compartilham a informação na web, buscou-se compreender quais elementos presentes no contexto social e na própria rede impactam nas atitudes dos jovens e como este público é visto pela sociedade. 


\section{Procedimentos metodológicos, coleta e análise dos dados}

O estudo, de natureza básica, construiu-se sob uma concepção pragmática, caracterizando-se como descritivo e de horizonte temporal transversal. A abordagem utilizada foi predominantemente qualitativa. Alguns dados, contudo, demandaram quantificação. A estratégia de investigação adotada foi a dos métodos mistos.

A fim de alcançar uma melhor compreensão a respeito das práticas informacionais dos adolescentes e de elucidar de que forma o contexto social influencia suas atitudes, dividiu-se a pesquisa em três etapas: (1) investigação de como os adolescentes buscam, usam e compartilham informações na internet e identificação das influências externas que impactam nas suas atitudes; (2) averiguação das percepções dos adultos quanto à adolescência; (3) comparação dos resultados das duas primeiras etapas, a fim de se verificar em que medida as práticas informacionais dos adolescentes na internet correspondem às percepções dos adultos sobre o público analisado.

O quadro 1 apresenta os métodos, as técnicas e os instrumentos de pesquisa utilizados.

Quadro 1 - Métodos, técnicas e instrumentos de pesquisa

\begin{tabular}{|l|l|l|l|l|l|}
\hline \multicolumn{2}{|c|}{ Etapas } & Métodos & $\begin{array}{l}\text { Técnicas de } \\
\text { coleta }\end{array}$ & $\begin{array}{l}\text { Instrumentos de } \\
\text { coleta }\end{array}$ & $\begin{array}{l}\text { Técnicas de } \\
\text { análise }\end{array}$ \\
\hline \multirow{2}{*}{$\mathbf{1}^{\text {a }}$} & $\begin{array}{l}\text { Busca, uso e } \\
\text { compartilhamento } \\
\text { de informação na } \\
\text { internet }\end{array}$ & Levantamento & $\begin{array}{l}\text { Entrevistas } \\
\text { Execução de } \\
\text { tarefa }\end{array}$ & $\begin{array}{l}\text { Roteiro de } \\
\text { entrevista } \\
\text { semiestruturada }\end{array}$ & $\begin{array}{l}\text { Análise de } \\
\text { conteúdo }\end{array}$ \\
\cline { 2 - 6 } & $\begin{array}{l}\text { Identificação de } \\
\text { influências externas }\end{array}$ & Levantamento & $\begin{array}{l}\text { Entrevistas } \\
\text { Execução de } \\
\text { tarefa }\end{array}$ & $\begin{array}{l}\text { Roteiro de } \\
\text { entrevista } \\
\text { semiestruturada }\end{array}$ & $\begin{array}{l}\text { Análise } \\
\text { funcional }\end{array}$ \\
\hline \multirow{2}{*}{$\mathbf{2}^{\text {a }}$} & $\begin{array}{l}\text { Averiguação das } \\
\text { percepções dos } \\
\text { adultos }\end{array}$ & $\begin{array}{l}\text { Discurso do } \\
\text { Sujeito Coletivo } \\
\text { (DSC) }\end{array}$ & Entrevistas & $\begin{array}{l}\text { Roteiro de } \\
\text { entrevista } \\
\text { estruturada }\end{array}$ & $\begin{array}{l}\text { Análise do } \\
\text { discurso por } \\
\text { meio do DSC }\end{array}$ \\
\hline $\mathbf{3}^{\mathbf{a}}$ & $\begin{array}{l}\text { Comparação dos } \\
\text { resultados }\end{array}$ & $\begin{array}{l}\text { Estudo } \\
\text { comparativo }\end{array}$ & $\begin{array}{l}\text { Resultados obtidos nas etapas 1 e } \\
\text { 2. }\end{array}$ & $\begin{array}{l}\text { Comparação } \\
\text { sincrônica }\end{array}$ \\
\hline
\end{tabular}

Fonte: Adaptado de Goulart (2018)

\subsection{Primeira etapa: como os adolescentes buscam, usam e compartilham informações na} internet e quais influências externas impactam nas suas atitudes

Esta etapa abarcou duas propostas que foram trabalhadas conjuntamente: (1) averiguação de como os adolescentes buscam, usam e compartilham a informação na internet; (2) verificação de elementos presentes na internet e no ambiente social capazes de influenciar as práticas informacionais do adolescente. 0 método de pesquisa adotado foi o levantamento 
(survey), que possibilita a coleta sistemática de dados sobre as pessoas, as suas preferências, os seus pensamentos e os seus padrões comportamentais (BHATTACHERJEE, 2012).

A coleta de dados foi realizada por meio de entrevista semiestruturada que, segundo Cunha (1982), se baseia em questões estruturadas, mas permite que o pesquisador se aprofunde nos tópicos que Ihe pareçam mais relevantes. Com duração média de 20 minutos, os inquéritos foram conduzidos em horários e locais escolhidos pelos participantes e tiveram o áudio gravado, mediante permissão dos respondentes, para posterior transcrição. Finda a entrevista, cada um dos participantes foi convidado a executar uma tarefa no computador, que consistiu na busca de três informações predeterminadas pela entrevistadora. Nesta etapa, a tela do computador foi gravada, por meio do software QuickTime Player. A atividade serviu para que se pudesse observar os métodos de busca adotados pelos adolescentes, os sítios preferidos, bem como o grau de dificuldade para encontrar o conteúdo procurado.

A amostra contou com um total de 20 adolescentes, sendo dez de cada sexo, com idades entre 13 e 18 anos, segmentados por tipo de escola em que estão matriculados. De acordo com Silva Filho e Moraes (2017), é considerável a diferença socioeconômica entre estudantes de escolas particulares e públicas, fator que impacta diretamente no desempenho dos discentes. Assim, com o intuito de diversificar o perfil dos participantes, dividiu-se a amostra em quatro grupos, cada qual com cinco indivíduos oriundos de instituições de ensino dos seguintes tipos:

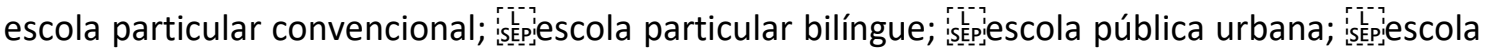
pública rural. isepipiDessa forma, foi possível averiguar se estudantes provenientes de educandários de perfis diversos apresentavam diferenças significativas em suas práticas informacionais.

Os dados coletados foram submetidos à análise de conteúdo e à análise funcional do comportamento. Para se apurar como os adolescentes buscam, usam e compartilham a informação na internet, empregou-se a análise de conteúdo. De acordo com Bardin (1977), a técnica, adaptável a vários campos de aplicação, consiste na descrição objetiva e sistemática das mensagens, com o intuito de interpretar o seu conteúdo. A estratégia possibilita a avaliação de questões relacionadas às atitudes, aos interesses e aos valores do grupo investigado (CUNHA; AMARAL; DANTAS, 2015).

Para a verificação dos elementos que, presentes na internet e no ambiente social, podem influenciar as práticas dos adolescentes, foi utilizada a análise funcional do comportamento. Esta técnica, proveniente da Análise do Comportamento, ocupa-se das variáveis externas ao indivíduo que o levam a determinado comportamento (SKINNER, 2003). O objetivo é identificar as relações causais presentes na interação entre o ser humano e o seu ambiente (NENO, 2003). 
Para o refinamento analítico das entrevistas e das tarefas, empregou-se o software MAXQDA, desenvolvido para dar suporte a pesquisas qualitativas e mistas. O programa permite a codificação dados, a marcação de informações, além de auxiliar na organização das ideias e teorias (VERBI GMBH, 2017). Assim, foi possível identificar regularidades nas falas, observar diferenças entre variáveis, quantificar alguns dados e tirar conclusões.

$\mathrm{Na}$ fase de pré-análise dos dados, optou-se por gerar uma nuvem de palavras com a totalidade das respostas de todos os entrevistados, a fim de se de identificar os termos mais frequentes nas narrativas dos adolescentes. De acordo com McNaught e Lam (2010), esta ferramenta oferece ao pesquisador uma visão geral dos principais temas abordados em um texto, servindo tanto para análise preliminar de algum conteúdo quanto para validação de descobertas posteriores. A partir da observação da nuvem de palavras foi possível perceber que os termos "gente", "pessoas", "pessoa", "amigos", bem como o nome de redes sociais como "Facebook" emergiram em destaque, o que leva à conclusão de que as relações interpessoais na rede configuram aspecto relevante no cotidiano dos adolescentes. A figura 1 apresenta a nuvem de palavras gerada a partir das respostas dos jovens.

Figura 1 - Nuvem de palavras das entrevistas de todos os participantes

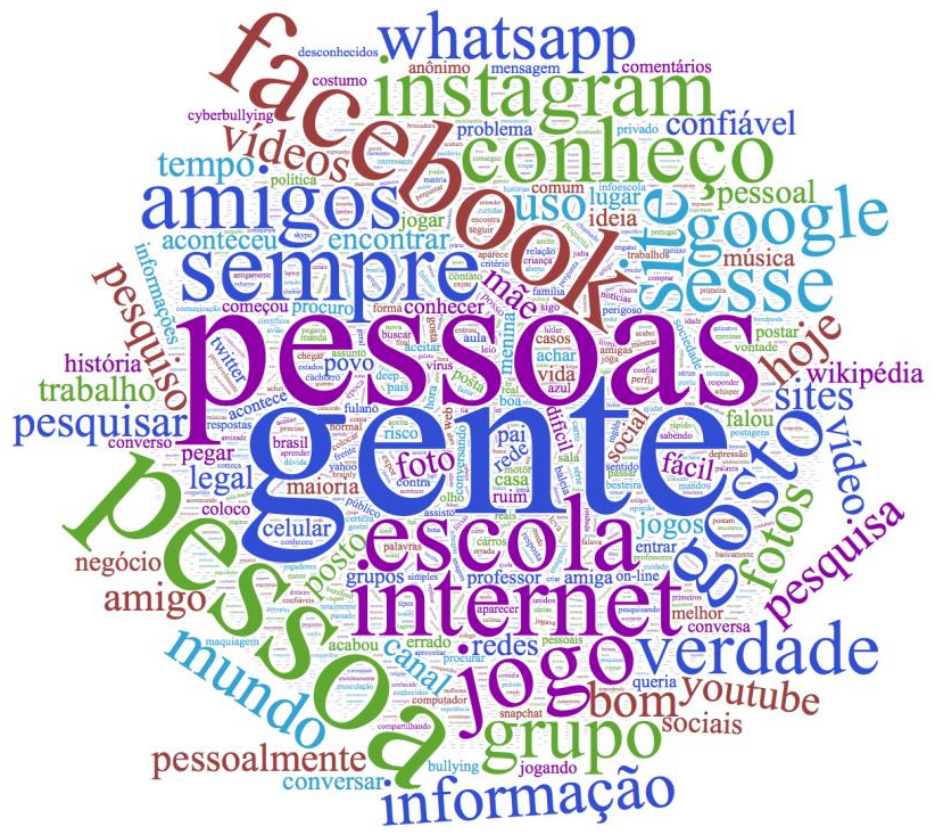

Fonte: Goulart (2018, p. 104)

Após esta etapa, o material coletado foi segmentado por assunto. Procedeu-se, em seguida, à sua codificação, que resultou em 15 tópicos que abrangiam desde dados quantitativos de uso da internet e sítios mais acessados para pesquisas pessoais e escolares, até assuntos de 
natureza qualitativa, como o comportamento dos jovens em redes sociais e jogos on-line, cyberbulling, experiências negativas vivenciadas na rede, dentre outros. Com isso, foi possível averiguar o modo como os adolescentes usam a web, bem como os fatores externos que os conduzem a tais comportamentos.

\subsection{Segunda etapa: percepções dos adultos em relação à adolescência}

Com o objetivo de identificar como o adolescente é visto pela sociedade, foram averiguadas as percepções dos adultos em relação a adolescência. Para tanto, aplicou-se a teoria das Representações Sociais, tal como proposta por Moscovici, em 1961, a partir de estudos em Psicologia Social. Esta abordagem busca explicar como o ser humano interpreta a realidade à sua volta, considerando que as representações sociais se constroem por meio de conhecimentos, valores, tradições e experiências compartilhadas por determinado grupo, e ajudam a situar o indivíduo na sociedade em que vive, além de familiarizá-lo com o novo (MOSCOVICl, 2015). O emprego da teoria das Representações Sociais auxilia na elucidação do modo como o conhecimento dos grupos reforça as identidades e influencia os pensamentos e a interação do indivíduo com o meio. Assim, a identificação das representações sociais da adolescência ajuda a situar o jovem em um contexto social, permitindo que se verifique se a imagem socialmente sedimentada do adolescente corresponde ao comportamento de tal público.

Para chegar a este fim, o método aplicado foi o Discurso do Sujeito Coletivo (DSC), técnica quali-quantitativa, elaborada por pesquisadores da Universidade de São Paulo (USP), para emprego em pesquisas de opinião, de representação social ou de atribuição social de sentido, que tenham como material de base investigativa depoimentos ou suportes de material verbal, como textos de revistas e jornais. A estratégia objetiva reunir vários discursos num único discurso síntese, fazendo com que o pensamento coletivo se expresse diretamente, mediante a instituição de um "sujeito" que incorpore o discurso coletivo (LEFEVRE; LEFEVRE, 2012).

A coleta de dados se fez por meio de entrevistas estruturadas, com duração média de cinco minutos, que ocorreram em locais e horários estabelecidos pelos participantes. Com o prévio consentimento de cada um dos respondentes, o áudio foi gravado e, posteriormente, transcrito e analisado.

Participaram da referida etapa 20 adultos, com idades entre 27 e 70 anos e nível de escolaridade entre ensino fundamental incompleto e pós-doutorado. O perfil dos entrevistados foi diferenciado em relação ao grau de contato com adolescentes. Por conseguinte, chegou-se a quatro grupos de cinco indivíduos cada, com a seguinte conformação: nenhum contato com 
adolescente; contato ocasional com adolescente; contato frequente com adolescente; convívio com adolescente na própria residência.

A técnica usada no exame dos dados foi a análise do discurso por meio do DSC e contou com o aporte tecnológico do software DSCSoft, expressamente desenvolvido para facilitar a realização de pesquisas quali-quantitativas nas quais se aplica a técnica do Discurso do Sujeito Coletivo (DSC). Com isso, as diversas percepções a respeito dos adolescentes foram categorizadas, a fim de gerarem os respectivos DSC.

Na fase de pré-análise, gerou-se uma nuvem de palavras com as respostas à seguinte pergunta: "Quais as cinco primeiras palavras que the vêm em mente quando pensa em istepiadolescência?". Como resultado, a palavra "rebeldia" foi a que mais apareceu nas respostas, demonstrando que, para os entrevistados, esta é a principal característica atribuída aos jovens. A figura 2 apresenta a nuvem de palavras obtida.

Figura 2 - Nuvem de palavras gerada a partir das cinco palavras mais lembradas pelos adultos quando pensam em adolescência

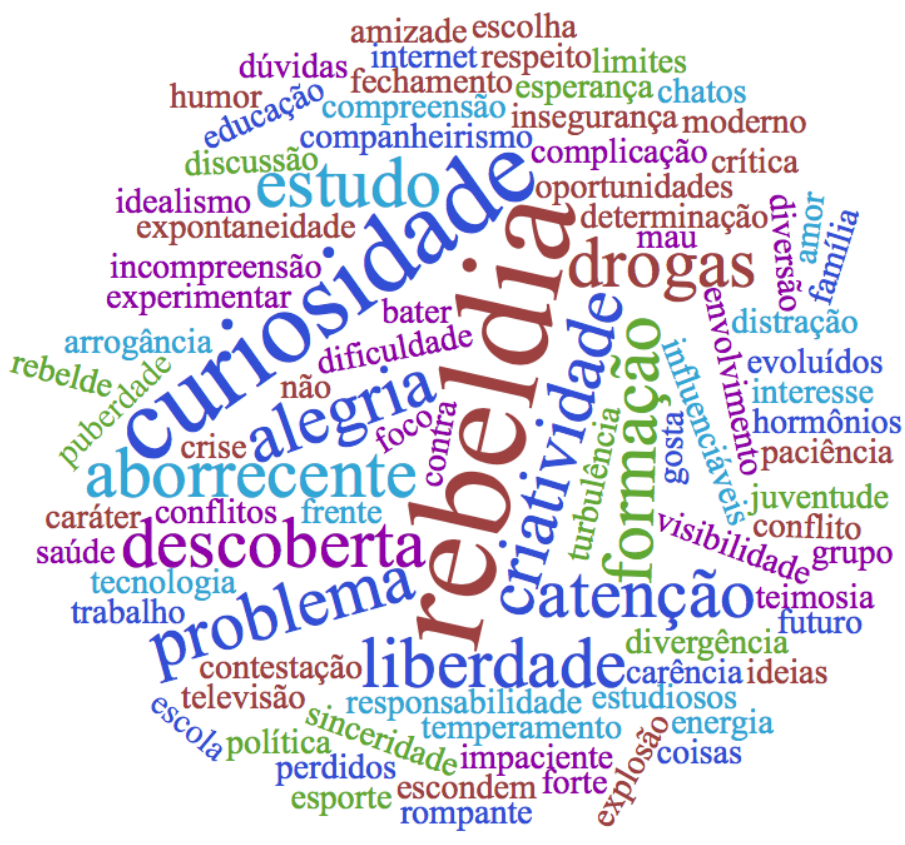

Fonte: Goulart (2018, p. 147)

As demais perguntas da entrevista serviram para a construção dos diversos DSC que ajudaram a compreender as percepções que os adultos apresentam acerca dos jovens. Assim, o material coletado foi categorizado de acordo com a ideia central (IC) contida em cada depoimento. Em seguida, os trechos com IC semelhantes foram transformados num discurso 
que sintetizasse a opinião dos participantes. Cada uma das quatro perguntas gerou diversos DSC, num total de 26 , abarcando impressões positivas, neutras e negativas em relação ao público pesquisado.

\subsection{Terceira etapa: comparação entre as práticas informacionais dos adolescentes na internet} e as percepções dos adultos sobre a adolescência

Nesta etapa, procedeu-se ao estudo comparativo para verificação dos elementos de convergência entre as práticas informacionais dos adolescentes na internet e as representações sociais da adolescência. O método, segundo com Schneider e Schmitt (1998), auxilia na identificação de regularidades, semelhanças e diferenças relacionadas a fenômenos sociais, sendo cabível tanto para a compreensão de um fenômeno singular quanto para a averiguação de uma série de eventos.

Para chegar aos resultados, realizou-se a comparação sincrônica, em que dois ou mais casos são investigados simultaneamente. Assim, foram comparados os resultados das etapas 1 e 2. Os 26 DSC formulados na segunda etapa foram sintetizados em 15 ideias, segregadas em positivas, neutras e negativas, todas expressando as percepções dos adultos quanto à adolescência, conforme apresentado no quadro 2 .

Quadro 2 - Percepções a respeito do adolescente

\begin{tabular}{|c|c|}
\hline & Adolescentes \\
\hline \multirow{4}{*}{$\begin{array}{l}\text { Ideias } \\
\text { Positivas }\end{array}$} & Têm muito acesso à informação em virtude da tecnologia \\
\hline & Estão numa fase de descobertas e busca de respostas \\
\hline & Preocupam-se com os estudos \\
\hline & Atualmente, têm mais escolhas \\
\hline \multirow{3}{*}{$\begin{array}{l}\text { Ideias } \\
\text { Neutras }\end{array}$} & São voltados para o mundo virtual \\
\hline & São influenciados pelos amigos \\
\hline & São influenciados pelo contexto social \\
\hline \multirow{8}{*}{$\begin{array}{l}\text { Ideias } \\
\text { Negativas }\end{array}$} & Não têm limites e fazem o que querem \\
\hline & São impacientes \\
\hline & São preguiçosos, inconsequentes e imaturos \\
\hline & São alienados \\
\hline & Comportam-se mal \\
\hline & Comportam-se de forma diferente em casa e na rua \\
\hline & Atualmente, a família está menos presente \\
\hline & Atualmente, têm menos responsabilidades e respeito \\
\hline
\end{tabular}

Fonte: Goulart (2018, p. 167)

As ideias coletadas foram inseridas no MAXQDA em forma de códigos, enquanto os resultados a respeito das práticas informacionais dos adolescentes ingressaram no software em formato de documento. O passo seguinte consistiu na comparação dos dados, a fim de se 
verificar quais características dos adolescentes apresentavam correspondência com as percepções dos adultos.

\section{Resultados}

Os resultados obtidos demonstraram que a maioria dos jovens pesquisados usa a internet todos os dias (19 entrevistados) e por longos períodos (12). Além disso, o celular é o equipamento mais usado para acesso à web por 12 respondentes. Dentre os alunos de escolas particulares (convencional e bilíngue), 7 afirmaram possuir banda larga em casa, enquanto nenhum estudante de escola pública (urbana e rural) tem este serviço. Tal fato demonstra maior facilidade de acesso à internet por participantes com nível socioeconômico mais alto. As principais atividades em que os participantes se engajam são realizar pesquisas escolares (14), buscar informações cotidianas (12) e usar redes sociais (11).

A totalidade dos entrevistados afirmou acessar a internet para buscar informações. Metade dos adolescentes, contudo, manifestou preocupação com a confiabilidade dos dados obtidos via web, sendo esta percepção mais comum entre os de sexo masculino (7). Não obstante, os adolescentes preferem buscar conteúdos na rede, em vez de consultar livros ou bibliotecas. Os sítios considerados por eles mais confiáveis são aqueles com terminação ". edu", ".org" e ".gov" (5) e o Infoescola (6). Tais dados encontram-se sumarizados na resposta de um participante a respeito da busca de informações na internet:

[...] porque tem o ponto positivo de ser de acesso rápido, em comparação com os livros, só que é muito difícil você confirmar se é verdade ou não. Com a facilidade que você tem pra postar, fica meio difícil você acreditar em tudo que aparece. Mas acho que é mais fácil que antigamente, quando você tinha que ir à biblioteca, procurar em enciclopédia.

O YouTube também despontou como um dos endereços preferidos dos adolescentes (20), tanto para busca de informações como para entretenimento. Alguns participantes (8) relataram que mantêm ou já mantiveram canal no sítio, embora tenham revelado sentirem-se desestimulados em publicar conteúdos, seja por dificuldades técnicas, seja pela falta de reação de outros internautas.

Diversos entrevistados (7), na sua maioria do sexo masculino (5), mencionaram ter o hábito de jogar on-line, inclusive com desconhecidos. Em relação às redes sociais, todos os participantes afirmaram serem usuários e, apesar de a maioria manter o seu perfil privado (17), muitos aceitam estranhos em suas redes sociais (7). Com isso, ficou claro que tanto os jogos online quanto a participação em redes sociais fazem parte do universo juvenil, são muito estimulados pelos amigos e desempenham papel importante nas interações pessoais, uma vez 
que servem tanto para constituir novas amizades quanto para reforçar os laços com interlocutores já conhecidos. O tema é explicitado no comentário de um participante:

[...] se eu conheço a pessoa e aí eu passo mais tempo com ela e todo dia a gente acaba jogando junto, aí sei lá, eu adiciono ela no Facebook e a gente conversa por lá e acabo conhecendo a pessoa mesmo, viro amigo dela. Então, se eu gostar da pessoa mesmo, se eu achar a pessoa legal, aí eu procuro ficar mais amigo dela, porque se eu gostei dela é legal interagir mais depois.

Para Nejm (2016), o compartilhamento de conteúdo na web equivale a uma forma de estreitar laços sociais e viabilizar trocas. De acordo com Sant'Anna e Garcia (2015), ao estender as amizades para o âmbito virtual, o jovem passa a ter contato com amigos durante todo o dia, o que lhe garante participação continua na rotina dos que lhe são próximos.

Poucos entrevistados (5) demonstraram algum nível de preocupação em proteger seus dados pessoais nas redes sociais, como se nota no depoimento de um entrevistado: "Eu não me exponho, então não vejo o risco de deixar público". Nas vezes em que tal inquietação foi manifestada, ficou claro que os principais influenciadores dos adolescentes, no que tange ao resguardo da privacidade, são os pais ou algum parente próximo.

Em relação aos riscos existentes na internet, as análises mostraram opinião divergente entre os participantes do sexo masculino e os do sexo feminino. Para os primeiros (7), a infecção do computador por vírus é considerada a mais séria ameaça da web. Já entre as adolescentes (9), aceitar estranhos nas redes sociais, travar contato pessoal com indivíduos que conheceram na internet e a exposição na rede são vistos como os maiores perigos. Tais percepções podem ser atribuídas ao fato de as mulheres, estatisticamente, serem alvo mais frequente de abusos, se comparadas aos homens.

Inquiridos a respeito de experiências ruins vivenciadas na web, nove participantes revelaram conhecer casos de pessoas que experimentaram algum tipo de situação adversa na rede, enquanto cinco entrevistados afirmaram já terem suportado algum constrangimento na internet. Sobre o assunto, um adolescente relatou o seguinte: "teve uma colega nossa lá na escola que enviou fotos íntimas pro namorado dela, só que aí eles terminaram e esse namorado dela postou a foto no Facebook, enviou pelo WhatsApp, aí todo mundo viu".

Apesar de tais vivências, a maioria dos adolescentes (12) não alterou seu comportamento, fato condizente com a argumentação de Nejm (2016), para quem os jovens mais se interessam pelas recompensas imediatas do relacionamento on-line, do que pelas possíveis consequências de seus atos.

A maioria dos entrevistados (15) declarou ter ciência de algum caso de cyberbullying. Contudo, de acordo com os respondentes, estas agressões costumam ter início em ambientes físicos, como as escolas, para depois migrarem para o ambiente virtual. Segundo Cerezo-Ramírez 
(2012), um dos problemas de tal prática é causar nas vítimas a sensação de impossibilidade de fuga, pois, uma vez que os ataques ocorrem em qualquer lugar em que se esteja on-line, não há onde a vítima se esconder.

Merece destaque, ainda, menções de encontros com desconhecidos, com quem o jovem havia interagido somente na web. Tal situação foi vivenciada por cinco entrevistados e qualificada como uma experiência positiva, o que evidencia certo grau de inconsequência de alguns adolescentes no que diz respeito à própria segurança, conforme se depreende da seguinte declaração: "Eu conversei primeiro privadamente, e a gente combinou de se encontrar, e eu não achei que algo ia dar errado".

Em relação à tarefa proposta, em que os entrevistados deveriam realizar três buscas de informação predeterminadas pela pesquisadora, os adolescentes demonstraram agilidade e desenvoltura para encontrar os conteúdos de interesse, não se preocuparam com o formato em que as informações foram disponibilizadas, além de se valerem de sítios que lhes são familiares, como o Google. Vale destacar, ainda, que as duas únicas bibliotecas on-line consultadas mostraram-se pouco intuitivas, o que desestimulou sobremaneira o participante que as acessou. Além disso, em uma das buscas, solicitou-se aos participantes que encontrassem, na web, um local para irem com o(a) namorado(a) ou com alguém em quem o indivíduo estivesse interessado. Neste tópico, chamou a atenção a variação de preços dos programas escolhidos, que deixou evidente a diferença socioeconômica entre eles: os estudantes de escolas particulares (convencional e bilíngue) escolheram programas caros ou muito caros, enquanto os estudantes de escola pública rural foram os únicos que se preocuparam em pesquisar o valor do passeio.

No que diz respeito às variáveis observadas na pesquisa, pode-se afirmar que, em relação ao perfil socioeconômico, os adolescentes de nível mais elevado detêm maior facilidade de acesso à web, por meio da banda larga, e não apresentam grande preocupação com gastos, como ficou evidente na atividade descrita. No quesito gênero, verificou-se que os participantes do sexo masculino se preocupam mais com a confiabilidade das informações contidas na web e são mais atraídos por jogos on-line. Além disso, homens e mulheres possuem percepções distintas em relação aos riscos existentes na web. Os demais tópicos do estudo não apresentaram disparidades relevantes em relação às variáveis.

No que tange às representações sociais da adolescência, diversas pesquisas sobre o tema apontam para a existência, na sociedade, de um estereótipo negativo atribuído a este público (MARTINS; TRINDADE; ALMEIDA, 2003; MENANDRO; TRINDADE; ALMEIDA, 2003; SALLES, 1995; SANTOS; ACIOLI NETO; SOUZA, 2011; PAIXÃO; ALMEIDA; ROSA-LIMA; 2012). Esta percepção foi confirmada em diversas narrativas dos adultos pesquisados, que descreveram os 
jovens como impacientes (2), preguiçosos (4), inconsequentes (4), imaturos (4), alienados (2), irresponsáveis e desrespeitosos (5).

Os adultos também expressaram a opinião de que os jovens têm muito acesso à informação em virtude da tecnologia (5) e que são muito voltados ao mundo virtual (4). Além disso, os participantes acreditam, em sua maioria, que os principais motivadores do comportamento juvenil são o contexto social (7) e a não imposição de limites pelos pais (6).

Na comparação entre as práticas informacionais dos adolescentes e as representações sociais da adolescência, as impressões positivas e neutras manifestadas pelos participantes adultos, embora minoritárias, revelaram maior correspondência com as atitudes dos jovens do que as opiniões negativas. Assim, as percepções dos adultos que encontraram equivalência com as características averiguadas nas práticas dos adolescentes foram as seguintes:

- os jovens são influenciados pelos amigos (12 correspondências);

- são muito voltados ao mundo virtual (11);

- têm muito acesso à informação, em virtude da tecnologia (8);

- recebem influência do contexto social (8);

- são preguiçosos, inconsequentes e imaturos (8);

- preocupam-se com os estudos (5);

- estão numa fase de descobertas e de busca por respostas (3);

- são impacientes (1).

A partir desses dados, conclui-se que os adolescentes sofrem bastante influência do grupo de amigos, sobretudo na prática de jogos e nas redes sociais. Os jovens voltam-se com frequência ao mundo virtual e possuem acesso facilitado à informação, em função da tecnologia. Assim, ao experienciarem uma fase de descobertas, usam com frequência a web para encontrar respostas aos assuntos que lhes interessam e para fins estudantis. No que diz respeito ao contexto social, observou-se que existe uma pressão social intensa para que todos passem a fazer uso das TIC.

Em relação às referências ao item "são preguiçosos, inconsequentes e imaturos", não há nada que confirme a suposta indolência que Ihes foi atribuída. Observa-se, entretanto, sinais de imaturidade e inconsequência nos adolescentes, principalmente, no que concerne às medidas de proteção que tomam em sua navegação na internet. Quanto à impaciência, o único excerto que remeteu a este item contém alusão ao imediatismo do jovem em busca de informações na internet.

Vale ressaltar, entretanto, que as impressões negativas em relação aos jovens, mesmo não correspondendo de todo aos achados da pesquisa, constituem um reforçador do estereótipo de rebeldia e conturbação atribuído a este público, capazes de interferir tanto no comportamento dos adolescentes quanto nos posicionamentos da sociedade em relação a eles. 
De acordo com Wachelke e Camargo (2007), a representação social serve de referência para a construção da representação individual, além de indicar à comunidade o modo de agir em relação a determinado objeto social.

Cabe lembrar, ainda, que a maior parte das percepções negativas atribuídas aos adolescentes não foi confirmada. Pelo contrário, os jovens entrevistados mostraram-se educados, corteses e atenciosos em todo o processo de realização da pesquisa. Ademais, acredita-se que, ao estereotipar a imagem do adolescente, impõe-se, tanto à sociedade quanto ao jovem, limitações na percepção das reais potencialidades deste público.

Os resultados expostos demonstram que o contexto vivenciado pelos adolescentes impacta suas atitudes na web, evidenciando como as relações do indivíduo com a informação são condicionadas socialmente. Tal constatação coaduna-se com a perspectiva da práticas informacionais, na qual "a informação é vista como uma construção social, algo que é definido no terreno da ação concreta de sujeitos em ações recíprocas (isto é, interações), tal como no contexto das 'comunidades discursivas'" (ARAÚJO, 2012, p. 146). Além disso, o direcionamento da pesquisa está de acordo com esta abordagem, que tem por objetivo a contextualização social do indivíduo (SAVOLAINEN, 2007).

\section{Considerações finais}

A pesquisa desenvolveu-se com o objetivo de analisar as práticas informacionais dos adolescentes na internet e demonstrou que a web está muito presente no cotidiano dos jovens, tanto para busca, como o para uso e compartilhamento de informações.

Uma vez que a perspectiva das práticas informacionais procura contextualizar o indivíduo socialmente, adotou-se uma abordagem interdisciplinar, com a aplicação de diversos métodos a fim de se chegar a um resultado satisfatório. Com isso, a análise de conteúdo permitiu a identificação de características de busca, uso e compartilhamento de informações pelos adolescentes. A análise funcional do comportamento mostrou-se útil na elucidação de elementos externos ao sujeito que influenciam suas atitudes. As representações sociais revelaram como o público pesquisado é percebido pelos adultos. Já a comparação dos resultados evidenciou que, nem sempre, os estereótipos existentes no meio social correspondem à realidade.

Confirmou-se, ademais, que a web impacta, fortemente, nos hábitos dos adolescentes, oferecendo-lhes possibilidades infinitas de acesso a conteúdo, compartilhamento de informações, além de perspectivas de interação e de exercício da criatividade. Também ficou evidente que, entre os jovens, as relações interpessoais extrapolam o contato presencial para adentrarem o universo virtual, tornando quase inexistente a diferença entre os dois ambientes. 
Além disso, a facilidade de acesso à web, amplificada pela disseminação dos smartphones, pelos serviços de internet oferecidos por operadoras de telefonia celular e pela propagação do wi-fi em espaços públicos alteraram a forma e a intensidade das interações no ambiente virtual, uma vez que tais tecnologias possibilitam conexão em tempo integral. A nova realidade torna o "estar on-line" quase uma imposição, principalmente por parte dos amigos, uma vez que, desconectado, o jovem fica alheio às ações dos grupos dos quais faz parte.

Finalmente, vale ressaltar que, se por um lado a conectividade ilimitada garante ao jovem acesso quase irrestrito à informação, ao entretenimento e às interações pessoais, por outro, pode configurar uma ameaça a sua privacidade, deixando-o em posição vulnerável ante os riscos existentes na web. Tal realidade, ademais, dificulta a demarcação de limites e o acompanhamento das atividades juvenis pelos pais ou responsáveis.

\section{Referências}

ALMEIDA, D. P. R.; ANTONIO, D. M.; BOCCATO, V. R. C.; GONÇALVES, M. C.; RAMALHO, R. A. S. Paradigmas Contemporâneos da Ciência da Informação: a recuperação da informação como ponto focal. Revista Eletrônica Informação e Cognição. v. 6, n. 1, p. 16-27, 2007. Disponível em: http://www.brapci.inf.br/ repositorio/2010/03/pdf fc4f01292e 0008415.pdf Acesso em: 22 out. 2018.

ARAúJO, C. A. A. Paradigma social nos estudos de usuários da informação: abordagem interacionista. Informação \& Sociedade: Estudos, João Pessoa, v. 22, n. 1, p. 145-159. 2012. Disponível em: http://www.ies.ufpb.br/ojs/index.php/ies/article/view/9896/7372 Acesso em: 02 out. 2017.

ARAÚJO, C. A. A. O que são "Práticas Informacionais"? Informação em Pauta, Fortaleza, v. 2, número especial, out. 2017.2 Disponível em: http://periodicos.ufc.br/informacaoempauta/article/view/20655/31084 Acesso em: 20 jun. 2018.

BACCEGA, M. A. Recepção: nova perspectiva nos estudos de Comunicação. Comunicação \& Educação. São Paulo, n. 12, p. 7-16, 1998 . Disponível em: http://www.revistas.usp.br/comueduc/article/view/36353/39073 Acesso em: 08 jan. 2017.

BACCEGA, M. A. Comunicação: interação emissão/recepção. Comunicação \& Educação, São Paulo, n. 23, p. 7-15, 2002.

BARDIN, L. Análise de Conteúdo. Lisboa: Edições 70, 1977.

BERTI, I. C. L. W.; ARAÚJO, C. A. A. Estudos de usuários e práticas informacionais: do que estamos falando? Informação \& Informação, Londrina, v. 22, n. 2, p. 389-401, 2017. Disponível em: 
http://www.uel.br/revistas/uel/index.php/informacao/article/view/31462 Acesso em: 04 jul. 2018.

BHATTACHERJEE, A. Social science research: principles, methods, and practices. Tampa Bay: USF Open Access Textbooks Collection, 2012. Book 3.

CAPURRO, R. Epistemologia e Ciência da Informação. ENCONTRO NACIONAL DE PESQUISA EM CIÊNCIA DA INFORMAÇÃO, 5., Belo Horizonte. 2003. Disponível em: http://www.capurro.de/enancib p.htm Acesso em: 01 mar. 2016.

CEREZO-RAMÍREZ, F. Bullying a través de las TIC. Boletín Científico Sapiens Research, v. 2, n. 2, p. 24-29, 2012. Disponível em: https://dialnet.unirioja.es/servlet/articulo?codigo=3973451 Acesso em: 13 jan. 2017.

COMITÊ GESTOR DA INTERNET NO BRASIL. TIC Kids Online Brasil 2015. Pesquisa sobre o uso da internet por crianças e adolescentes no Brasil. São Paulo, 2016. Disponível em: http://www.cetic.br/media/docs/publicacoes/2/TIC Kids 2015 LIVRO ELETRONICO.pdf Acesso em: 10 jan. 2017.

CUNHA, M. B. da. Metodologias para estudo dos usuários de informação científica e tecnológica. Revista de Biblioteconomia de Brasília, v. 10, n. 2, p. 5-19, 1982.

CUNHA, M. B. da; AMARAL, S. A. do; DANTAS, E. B. Manual de Estudo de Usuários da Informação. São Paulo: Atlas, 2015.

FRIEDMAN, T. O mundo é plano: uma breve história do século XXI. Rio de Janeiro: Objetiva. 2005.

FUNDO DAS NAÇÕES UNIDAS PARA A INFÂNCIA (UNICEF). 0 uso da internet por adolescentes. Brasília, 2013.2 Disponível em: https://www.unicef.org/brazil/pt/br uso internet adolescentes.pdf Acesso em: 05 fev. 2017.

GOULART, A. H. Adolescência, internet e práticas informacionais. 2018. 203 f. Dissertação (Mestrado em Ciência da Informação) - Universidade de Brasília, Brasília, 2018. Disponível em: http://repositorio.unb.br/handle/10482/32018 Acesso em: 24 out. 2018.

HJØRLAND, B. Epistemology and the socio-cognitive perspective in information science. Journal of the American Society for Information Science and Technology, v. 53, n. 4, p. 257-270, 2002.

LEFEVRE, F.; LEFEVRE, A. M. Pesquisa em representação social: um enfoque qualiquantitativo. 2. ed. Brasília: Liberlivro, 2012.

MARTINS, P. de O.; TRINDADE, Z. A.; ALMEIDA, A. M. de O. O Ter e o Ser: Representações Sociais da Adolescência entre Adolescentes de Inserção Urbana e Rural. Psicologia: Reflexão e Crítica, 
v. 16, n. 3, p. 555-568, 2003. Disponível em: http://www.scielo.br/pdf/prc/v16n3/v16n3a14.pdf Acesso em: 03 jan. 2018.

MCKENZIE, P. A model of information practices in accounts of everyday-life information seeking. Journal of Documentation. v. 59, n. 1, p. 19-40, 2003.

MCNAUGHT, C.; LAM, P. Using Wordle as a supplementary research tool. The Qualitative Report. v. 15, n. 3, p. 630-643, 2010. Disponível em: http://nsuworks.nova.edu/cgi/viewcontent.cgi?article=1167\&context=tar Acesso em: 1 dez. 2017.

MENANDRO, M. C. S.; TRINDADE, Z. A.; ALMEIDA, A. M. de O. Representações sociais da adolescência/ juventude a partir de textos jornalísticos (1968-1974 e 1996-2002). Arquivos Brasileiros de Psicologia, v. 55, n. 1, p. 42-55, 2003.

MOSCOVICl, S. Representações Sociais: investigações em psicologia social. 11. ed. Petrópolis, RJ: Vozes, 2015.

NENO, S. Análise funcional: definição e aplicação na terapia analítico-comportamental. Revista Brasileira de Terapia Comportamental e Cognitiva, São Paulo, v. 5, n. 2, p. 151-165, dez. 2003. Disponivel em: http://pepsic.bvsalud.org/scielo.php?script=sci_arttext\&pid=S151755452003000200006\&lng=pt\&nrm=iso Acessos em: 29 nov. 2017.

NEJM, R. Minha privacidade, nossas regras: estratégias sociais de manejo da privacidade entre adolescentes. In: COMITÊ GESTOR DA INTERNET NO BRASIL. TIC Kids Online Brasil 2015. Pesquisa sobre o uso da internet por crianças e adolescentes no Brasil. São Paulo, 2016. Disponível em: http://www.cetic.br/media/docs/publicacoes/2/TIC Kids 2015 LIVRO ELETRONICO.pdf Acesso em: 10 jan. 2017.

PAIXÃO, D. L. L.; ALMEIDA, A. M. de O.; ROSA-LIMA, F. Representações Sociais da adolescência por adolescentes e jovens. Psicologia e Saber Social, v. 1, n. 2, p. 278-294, 2012.

PALFREY, J. G.; GASSER, U. Nascidos na era digital: entendendo a primeira geração de nativos digitais. Porto Alegre: Artmed, 2011.

ROCHA, J. A. P.; DUARTE, A. B. S.; PAULA, C. P. A. Modelos de práticas informacionais. Em Questão. Porto Alegre, v. 23, n. 1, jan./abr. 2017. Disponível em: http://www.seer.ufrgs.br/EmQuestao/article/view/67014 Acesso em: 28 jun. 2018.

SALLES, L. M. F. A Representação Social do Adolescente e da Adolescência: um Estudo em Escolas Públicas. Cadernos de Pesquisa; São Paulo, n. 94, p. 25-33, ago. 1995.

SANT'ANNA, H. C.; GARCIA, A. Tecnologia da Comunicação e Mediação Social: o papel da telefonia celular na amizade entre adolescentes. Interação em Psicologia. v. 15, n. 1, p. 37-50, 
2011. Disponível em: http://revistas.ufpr.br/psicologia/article/view/7537/16413 Acesso em 13 jan. 2018.

SANTOS, M. F. de S.; ACIOLI NETO, M. de L.; SOUZA, Y. S. de O. Adolescência em revistas: um estudo sobre representações sociais. Psicologia: Teoria e Prática. v. 13, n. 2, p. 103-113, 2011. Disponível em: http://editorarevistas.mackenzie.br/index.php/ptp/article/viewFile/2566/2980 Acesso em: 03 jan. 2018.

SAVOLAINEN, R. Information Behavior and Information Practice: Reviewing the "Umbrella Concepts" of Information-Seeking Studies. Library Quarterly, v. 77, n. 2, p. 109-132, 2007. Disponível em: http://www.jstor.org/stable/10.1086/517840?seq=1\#page scan tab content Acesso em: 27 dez. 2016.

SCHNEIDER, S.; SCHIMITT, C. J. O uso do método comparativo nas Ciências Sociais. Cadernos de Sociologia, Porto Alegre, v. 9, p. 49-87, 1998.

SILVA FILHO, G. A. da; MORAES, G. H. Comparando desempenhos de diferentes tipos de escola de ensino médio: uma aproximação de medida de valor adicionado. Boletim Na Medida, v. 6, n. 12. Brasília: Inep/MEC, 2017. Disponível em: http://inep.gov.br/informacao-da-publicacao//asset_publisher/6JYIsGMAMkW1/document/id/1088546 Acesso em: 29 nov. 2017.

SKINNER, B. F. Ciência e Comportamento Humano. 11. ed. São Paulo: Martins Fontes, 2003.

SPIZZIRRI, R. C. P.; WAGNER, A.; MOSMANN, C. P.; ARMANI, A. B. Adolescência conectada: Mapeando o uso da internet em jovens internautas. Psicologia Argumento, v. 30, n. 69, p. 327335, 2012. Disponível em: http://www2.pucpr.br/reol/index.php/PA/pdf/?dd1=5979 Acesso em: 5 fev. 2017.

TABOSA, H. R.; TAVARES, D. W. S.; NUNES, J. V. História e epistemologia da Ciência da Informação: Abordagem social em foco. Revista Interamericana de Bibliotecología, v. 39, n. 3, p. 289-300, 2016. Disponível em: https://aprendeenlinea.udea.edu.co/revistas/index.php/RIB/article/view/22702/2078270 Acesso em: 26 jun. 2018.

THOMPSON, J. B. A mídia e a modernidade: uma teoria social da mídia. 10. ed. Petrópolis: Vozes, 2008.

WACHELKE, J. F. R.; CAMARGO, B. V. Representações Sociais, Representações Individuais e Comportamento. Revista Interamericana de Psicologia/ Interamerican Journal of Psychology. Porto Alegre, v. 41, n. 3, p. 379-390, 2007. Disponível em: http://pepsic.bvsalud.org/pdf/rip/v41n3/v41n3a13.pdf Acesso em: 2 jul. 2015.

VERBI GMBH. Análise qualitativa de dados e métodos mistos com o MAXQDA. 2017. Disponível em: http://www.maxqda.com/portugues-do-brasil Acesso em: 04 dez. 2017. 
